\title{
On Fertile Functionings: A Response to Martha Nussbaum
}

Jonathan Wolff and Avner de-Shalit

Jonathan Wolff is Professor of Philosophy at University College London, UK

Avner de-Shalit is Professor of Political Science at The Hebrew University of Jerusalem, Israel.

We are delighted to have the opportunity to respond to Martha Nussbaum's excellent Creating Capabilities. In that book Nussbaum pays us the great compliment of discussing some aspects of our own book Disadvantage (Wolff and de-Shalit, 2007), both endorsing some of our analysis, yet also entering some criticisms. We would like here to explain the issues and provide our response.

The ideas that Nussbaum endorses, albeit with qualifications, from our work are essentially three. The first is the idea of 'secure functionings', re-named by Nussbaum 'capability security' (Nussbaum, 2011, p. 43): that it is important to people not only that they enjoy a certain level of functioning but also that they are able to sustain it over time. Furthermore, it is important to people to be free from the worry, which people whose functioning is at an ongoing risk, experience. The second is that of 'corrosive disadvantage', where a disadvantage in one domain is likely to spread its effects to other areas. Drug addiction, homelessness ${ }^{1}$, or possibly uncontrollable debt are examples of corrosive disadvantages. The third is 'fertile functioning' where an achievement in one area is likely to have benefits elsewhere. Self-control is increasingly being argued to be a fertile functioning in this sense, while we speculated that 'affiliation' and 'having friends' in the sense of having a supportive social network would also be fertile. We also, quite naturally, suggest that it should be a priority for public policy to take preventative steps to block the formation of corrosive disadvantages, and to build fertile functionings. 
Parenthetically, although it will play no further part in this discussion we would also like to introduce an additional idea that is implicit in our previous analysis, that of 'multiple, severe disadvantage'. This is the idea of being in a badly disadvantaged situation, but the available opportunities to improve your situation puts you at grave risk of becoming worse off still; for example someone who can only obtain very dangerous work, or, perhaps, can only feed themselves by breaking the law. Such people are more or less stuck in a disadvantaged position unless something can be done to break the structural impediments they face.

We should make clear that while the concepts we use are novel, they are, perhaps, implicit in much social science, and one could claim that they are indeed derived from the capability approach. So our hope is that these concepts can be easily incorporated into philosophical and empirical analysis.

It is one of the names, however, that Nussbaum initially objects to, and this leads to more substantial philosophical issues. Nussbaum is not happy with the idea of 'fertile functionings' suggesting that our liking for alliteration has stood in the way of clear thought (p. 44). We should, she feels, have talked about 'fertile capabilities' and more generally suggests that we are unclear in whether our analysis focuses on capabilities or functionings. Well, we must concede a weakness for alliteration, but nevertheless in this case we feel it aids, rather than impedes, clear analysis.

The issue is this. Let us use the neutral term 'fertile advantages', and ask whether further advantages will come from having a capability or from a functioning. Which would it be? Before settling this issue we should note that in Disadvantage we expressed at least three concerns about the notion of capability which stopped us from endorsing it whole-heartedly in our analysis.

One problem is the question of the 'gap' between capabilities and functionings. That is, when do I have a capability for affiliation, for example? Suppose I move 
on my own to a new town, but there are many opportunities for meeting new people. There is a community centre, evening classes, hobby clubs, political meetings, support groups, and so on. But I haven't done anything to take advantage of these opportunities and I spend my free time alone. Do I have the capability for affiliation or not? I do in the sense that I could achieve it if I chose, and worked at it for a while. Or suppose I live in a town where there are none of these things, but I could easily move to the town with the facilities just mentioned. Do I still have the capability? Or on the contrary do we want to say that actually I only have the capability when I do in fact have a social network? If so then the distinction between capability and functioning appears to have collapsed (more on this shortly). If we deny this identification then we need to say at what point the opportunity is too remote to constitute a capability. The more remote, the less valuable an unrealised capability; the less remote the less we can insist on a clear distinction.

The second problem is that the two notions together are rather confusing: it is not always really clear when something is a capability and when it is a functioning. Many functionings are in fact capabilities for other functionings. For example, literacy is a capability and reading is a functioning. But reading is not only a functioning; it is, at the same time, a capability, e.g. for studying, or for driving. As David A. Clark argues $(2005,1361)$, many functionings, from recreational activities, through spiritual activities to psychological achievements also represent necessary inputs for good living, and therefore for other functionings.

The third problem is epistemological. Functionings can be observed, capabilities cannot or at least not so easily, and this will create severe difficulties for policy. This at least provides a pragmatic reason for focusing on functionings. Once more we are very far from being the first authors to point this out, but we mention it here just to record the reservations that prevent us from adopting the capability approach in unqualified form. 
However, there are further philosophical concerns that lay under our difficulties with the idea of a capability that we did not articulate earlier and now make us think that the terrain is even more complex than we have realised. If someone has a realised capability then what exactly do they have? We believe that in the paradigm case there will be at least three things we can say:

i) They have achieved the functioning.

ii) They have had the choice whether or not to have achieved the functioning. (Freedom whether to achieve.)

iii) They have achieved the functioning in their own way. (Freedom how to achieve.)

The second and third of these are clearly forms of freedom, and we feel that they could be easily confused, at some cost. Consider, for example, the realised capability for bodily health. Someone who has this capability will be healthy (feature i) and probably have done so at least in part by taking control over their own health (feature iii). Martha Nussbaum says that the capabilities approach 'commits itself to respect for people's powers of self-definition' (p. 18). This can be read as either feature (ii) or (iii) or both. But how important is it that people have the choice whether or not to achieve bodily health? Do we value the pure freedom of choice whether to be healthy? No doubt philosophers' examples can be concocted, but let us think about some real cases.

Consider, for example, men in a district of Glasgow, discussed by Michael Marmot and associates, where male life expectancy is 54 (CSDH, 2008, p. 32). These are men who all have access to the Scottish health care system, which is free at the point of use. Their low life expectancy is largely a result of life-style choices: heavy drinking and smoking, injecting drug use, very poor diet, and violence. Some men in this district nevertheless avoid these problems, and live to a much greater age, suggesting that in some sense all men in the area have the freedom to achieve health or to fail to achieve it (this is not to say anything about blame or responsibility). Yet despite Nussbaum's suggestion that we should be interested in 'health capability' rather than 'health' as only the former 'honors 
the person's lifestyle choices' (p. 26) in this case we do not celebrate the freedom of choice of the men who die young, but express concerns about the nature of their environment which has led them to make their choices. Freedom whether or not to achieve bodily health rarely seems valuable in itself. ${ }^{2}$

A contrasting example is religious observance, where from a social point of view the two different freedoms identified above are the important features, and whether people are actually religious is a matter of social indifference. Our view, however, is that many of the capabilities under discussion are more like bodily health than religious observance, in that much value is in the achievement, and, furthermore, part of the good is its being secured. (Mental health and bodily integrity are good examples). In this case, the freedom whether or not to achieve them is generally not of high value, although it is important that people achieve them their own way.

This leads us to think that the important aspect of the capability approach is, in general, less about the freedom whether or not to achieve a functioning, but rather about being able to take control over the way in which the functioning is achieved: to achieve things one's own way. Nussbaum, of course, recognises the importance of achieving things one's own way, but at the same time, we think, over-emphasises the importance of the freedom not to achieve some functionings at all, However, there are of course exceptions as different aspects of the human good have different roles in individual lives.

Let us return, then, to the issue of whether we should have used the idea of 'fertile capabilities' rather than 'fertile functionings'. We have to confess that we see some problems in doing so. Apparently there will only be a practical difference where a capability is unrealised. But then, how can an unrealised capability be fertile? Only, presumably if it can instantly be realised, but then it is the functioning that is doing the work.

Take the example of affiliation as a fertile advantage. How might it be so? An example comes from work in India where it has been shown that 'empowering 
women's groups' has beneficial effects for the mental health of new mothers, among other significant benefits (Tripathy et al. 2010). How so? Presumably because women learn from each other; they are stronger together; they support each other in times of need and hardship; and become more confident individually. The unrealised capability for affiliation will have none of these effects.

Now, the defence of Nussbaum's critique could be to return to our earlier distinctions, and concede that while an unrealised capability will not be fertile, there is still a distinction between a realised capability and a (bare) functioning. It could be argued that if a functioning is not acquired by these women in their own ways, then the beneficial effects will not be forthcoming. Here we can concede that it appears women have to 'own' the process for themselves for it to be effective in generating a beneficial form of affiliation. But is that a way of saying that the functioning without ownership is ineffective, or rather that the functioning would not actually be acquired without a sense of ownership?

But to make our position clear, we do not believe that an unrealised capability can be fertile, unless it can be realised instantly. Where we may agree with Nussbaum is that in some cases a functioning can be more or less fertile depending on how it is acquired. But even so, we would not wish to apply this to every case. Will-power is increasingly regarded as fertile, yet the manner in which it is acquired seems to be irrelevant to its effectiveness. Furthermore, as we argued above, and this may lead to the confusion, a fertile advantage is, in itself, a (perhaps unrealised) capability for other advantages. But this point, we think, is most clearly made if we remain with our alliterative usage, and by suggesting that a fertile functioning is a functioning in one respect which itself contains further capabilities in others.

Last but not least, it seems to us that Nussbaum's critique reflects a different political standpoint to that we would wish to take. Those who are satisfied with a situation whereby the state limits itself to offering capabilities - even if these are secure capabilities - rather than securing functionings, shift the responsibility for 
a person's well being to that person. They claim that it is not the state's goal to see that the horse does drink; it should only see that the horse gets a chance to drink from the watering trough. Now, we agree that it is important to expect people to take some responsibility for their well being both because often this is part of their way to get out of poverty or disadvantage ${ }^{3}$ and because if all disadvantaged people fail to take responsibility this might damage the welfare state's legitimacy. However, if one has in mind the most disadvantaged, those who experience a clustering of disadvantages, then, we believe, one should also consider how to secure their functionings, not only their capabilities.

\section{Notes}

${ }^{1}$ Being homeless implies, for example, that one finds it difficult to compete for jobs because of the demand by interviewers to supply an address when applying for the job.

${ }^{2}$ In fairness we should note that Nussbaum considers this objection in very abstract form (citing Richard Arneson, 2000). She dismisses it on grounds of 'the high value we assign to choice' (p. 26). We believe it is possible to respect choice - choice in the way that people achieve good health - without giving high value to the choice whether or not to become healthy. To be clear, we accept that it is legitimate for people to make choices that may damage their health, but this is as a side-effect of other activity that they find valuable, rather than a freedom that is good in itself.

${ }^{3}$ Homeless people are often encouraged to take responsibility not only to themselves but also to other creatures, namely dogs. The idea behind this policy is that because they have become homeless they don't practice any responsibility; they need not clean and maintain their home, cook for themselves or others, pay bills, and so on; so taking responsibility for the dog is a first step towards becoming accustomed again to practicing responsibilities.

\section{References}


Arneson, Richard (2000) 'Perfectionism and politics' Ethics 111, 37-63

Clark, David A. (2005) 'Sen's capability approach and the many spaces of human well-being', The Journal of Development Studies Vol. 41, 1339-1368

CSDH (2008), Closing the Gap in a Generation: Report of the Commission on the Social Determinants of Health. Final Report of the Commission on Social Determinants of Health, World Health Organization, Geneva.

Nussbaum, M. C. (2011), Creating Capabilities: The Human Development Approach, Belknap Press, Harvard.

Tripathy, P., Nair, N., Barnett, S., Mahapatra, R., Borghi, J. Rath, S., Rath, S., Gope, R., Mahto, D., Sinha, R., Lakshminarayana, R., Vikram, P., Pagel, A. P., Costello, A. (2010), 'Effect of a participatory intervention with women's groups on birth outcomes and maternal depression in Jharkhand and Orissa, India: a cluster-randomised controlled trial'. Lancet,375(9721), pp. 1182-92. Wolff, J. and de-Shalit, A. (2007), Disadvantage, Oxford University Press, Oxford. 